\title{
Trabalho, organização e pessoas com transtornos mentais graves
}

\author{
Paulo César Zambroni-de-Souza ${ }^{1}$ \\ Universidade Estadual do Rio de Janeiro
}

\begin{abstract}
Este artigo aborda o trabalho, em especial o trabalho de pessoas com transtornos mentais graves. Encontra-se socialmente predominante a visão construída na história da psiquiatria de que essas pessoas não podem trabalhar, que são incapazes de adequar-se às exigências presentes em qualquer meio de produção ou serviço. Esse julgamento de incapacidade acabou por aumentar o isolamento e impedir uma aproximação maior dessas pessoas com o trabalho. A ergologia, abordagem desenvolvida para compreender e transformar o trabalho, foi tomada aqui como ferramenta principal para pensá-lo em sua relação com pessoas que sofrem de transtornos mentais graves, considerando a realidade dos mundos do trabalho e da reforma psiquiátrica no Brasil hoje.
\end{abstract}

Palavras-chave: Trabalho, Transtorno mental, Ergologia, Competência, Reforma psiquiátrica.

Labor, organization and people with severe mental ill

This paper deals with labor, particulary the labor of people with severe mental ill. It has been widely spread in the point of view proposed in the history of psychiatry, according to which these people may not work and are incapable to address the demands from the production and service means. It helped to increase the isolation of these people, wiping them away from the work environment. In this work the ergology, developed approach to understand and transform the labor, has been taken as the main tool to think it in to relation with these people, taking into consideration the reality of the worlds labor and the psychiatric reform in Brazil.

Keywords: Labor, Mental illness, Ergology, Competence, Psychiatrical reform.

E ste artigo pretende pensar questões relativas ao lugar do trabalho na vida de pessoas com transtornos mentais graves. Sabemos que essa expressão - pessoas com transtornos mentais graves - não designa uma categoria única, ou seja, a partir dela pode-se pensar em pessoas e situações muito diversas. Sabemos também que quando utilizam-se categorias abstratas, que não se referem a nenhum grupo ou situação específicos, corre-se o risco de cair em generalizações vazias. Entretanto, pensamos não ser satisfatório o uso de entidades nosológicas como as da CID-10 (Organização Mundial de Saúde) ou as da revisão do DSMIV (Associação Psiquiátrica Americana), que procuram classificar o sofrimento psíquico em parâmetros clínicos supostamente representativos de uma neutralidade científica, mas que acabam por empobrecer seu objeto, reduzindo pessoas a transtornos mentais, e podem trazer consigo a tradição de uma psiquiatria que, desde Pinel, acabou por isolar pessoas do trabalho e do convívio social aberto. Por outro lado, pensamos que a noção de "existência-sofrimento do sujeito em relação com o corpo social” (Rotelli \& Amarante, 1992, p. 52), proposta por Basaglia, que busca superar os diagnósticos propostos pela psiquiatria por reconhecer que estes assumem "(...) o valor de um rótulo que codifica uma passividade dada como irreversível” (Basaglia, 1985, p. 108), é por demais genérica e não dá conta de situações de vidas singulares.

Apesar dessa dificuldade inicial de conceituação, estamos admitindo a existência de pessoas que em determinados momentos de suas vidas experimentam alterações psíquicas,

1 Doutorando do Programa de Pós-Graduação em Psicologia Social da Universidade do Estado do Rio de Janeiro, com estágio de doutoramento na Université de Provence, França, fomentado pelo programa PDEE/CAPES. Psicólogo e mestre em Psicologia pela Universidade Federal do Rio de Janeiro. 
ocasiões em que não conseguem estabelecer uma boa relação consigo mesmas nem com quem está ao seu redor, condições que podem dificultar a cooperação que a atividade de trabalho exige. Na tentativa de classificação desses fenômenos, Pinel escreve sua nosografia (Bercherie, 1989, p. 34), a CID apresenta diversas categorias, Basaglia fala em existênciasofrimento, as pessoas não iniciadas em psiquiatria ou saúde mental, por sua vez, utilizam várias expressões. Não é nossa intenção neste artigo propor possíveis desembaraços a essa questão classificatória.

Vamos nos contentar, no momento, em admitir que pessoas apresentam sofrimento psíquico em diferentes graus e em situações diversas durante suas vidas. Algumas são freqüentemente enquadradas em categorias diagnósticas e recebem tratamentos. Vamos tomar como ponto de partida que, ao defrontarem-se com algumas dessas crises, elas geralmente afastam-se ou são afastadas do trabalho. Aquelas que tinham emprego freqüentemente o perdem, as que tinham trabalho informal deixam de tê-lo, por vezes, perdem o direito de realizar até trabalhos domésticos em suas próprias casas. Optamos por utilizar neste artigo a expressão "transtornos mentais graves" na medida em que podemos nos valer de conhecimentos produzidos no campo da psiquiatria, cuidando para que eles não correspondam "(...) a uma etiquetagem e a uma estigmatização do doente (...)" (Basaglia, 1977, p. 13). Vamos guardar o termo "grave" por entender que as pessoas tomadas como foco de reflexão neste texto vivenciam situações em que os transtornos mentais podem trazer grande sofrimento. Não pretendemos, no entanto, estabelecer critérios de gravidade como a CID-10 ou o DSM-IV fazem. Por outro lado, entendemos que esses mesmos fenômenos, as peculiaridades vividas em uma situação de trabalho e a própria vida não se limitam ao que a psiquiatria ou qualquer outro saber pode produzir.

Sabemos, com a ergologia, que o trabalho está sempre inserido na história (da espécie, da sociedade, do sujeito) e nela intervém, de modo que tentar compreendê-lo supõe também considerar as condições conceituais e históricas nas quais cada pessoa é confrontada (Schwartz, 1995a, p. 418), de maneira que faz-se necessário de início tratar da relação das pessoas com os transtornos mentais com o trabalho e com a psiquiatria.

A ergologia é uma abordagem que tem como principal centro de desenvolvimento o Departamento de Ergologia, na Université de Provence, França, cujo diretor científico é o professor Yves Schwartz, que tem a atividade como ponto de partida e de chegada para compreender o humano, especificamente no trabalho. Por ter como objetivo compreender e transformar o trabalho, essa abordagem será tomada como principal fonte de inspiração teórica neste artigo.

\section{Trabalho, psiquiatria e transtornos mentais}

Desde o início da psiquiatria, trabalho e loucura andam, paradoxalmente, ao mesmo tempo juntos e separados. A psiquiatria nasceu trazendo a loucura para o campo de cuidados da medicina. Pinel inaugurou o alienismo fundando o asilo, no mesmo momento que Tuke fundou o retiro. Às pessoas confinadas nesses espaços era atribuída uma "incapacidade de trabalhar", que confirmava a necessidade de sua reclusão para tratamento, conforme mostra Foucault (1987, p. 78): “(...) o momento em que a loucura é percebida no horizonte social da pobreza, da incapacidade para o trabalho, da impossibilidade de integrar-se no grupo (...)”. Esse julgamento de incapacidade para trabalhar coincide com um momento histórico em que os próprios trabalhadores eram considerados também incapazes de conduzir suas próprias vidas e de pensar por si mesmos (Castel, 2001, p. 305). De uma certa forma, então, pesava sobre o operário e sobre o louco um julgamento de incapacidade. 
Para que os operários se libertassem desse julgamento - ainda que parcialmente, uma vez que esse preconceito não está totalmente superado - foi necessário um longo processo, que passou também pela luta para ter sua voz ouvida e seus direitos garantidos. Encontramos exemplos dessa luta no movimento dos trabalhadores, com os operários franceses, anos mais tarde, na década de 1940, reivindicando uma medicina do trabalho que não estivesse apenas a serviço da empresa, como mostra Billiard (2001, p. 55), ou ainda com os próprios operários buscando ocupar um lugar de importância na detecção e controle da nocividade do trabalho, evidenciando seu papel na construção dos conhecimentos sobre sua própria saúde no trabalho, o que ficou conhecido como Movimento Operário Italiano de luta pela saúde (Oddone, 1981). No Brasil, a era Getúlio Vargas desenvolveu um sindicalismo atrelado ao Estado no momento em que o presidente da república intitulava-se "pai dos pobres". Um amplo questionamento do lugar dos sindicatos frente ao poder do governo federal, sobretudo durante os anos da ditadura militar, contribuiu para a construção de outra relação dos trabalhadores com os governantes e empresários, contrariando a visão de incapacidade do operário para pensar, a qual, aliás, foi um dos sustentáculos do taylorismo².

O desenvolvimento do modo de produção capitalista e a ascensão da burguesia trouxeram, durante o século XVIII na Europa, a necessidade do "trabalho livre" em contraposição ao trabalho de servos e escravos (Castel, 2001, p. 232). No entanto, essa liberdade não se tornou direito de todos. Como havia a necessidade de acumulação e reprodução ampliada de capital através da produção de bens materiais, aos operários foi possível viver, e freqüentemente morrer, nesse tipo de liberdade para vender sua força de trabalho no mercado capitalista. Enquanto isso, o louco foi trancado no hospício, não podendo sequer reivindicar sua entrada no circuito da produção.

No manicômio o trabalho aparece por dois ângulos: aquele designado louco, se por um lado foi julgado incapaz de trabalhar, por outro, no tratamento que a medicina lhe dispensou, o trabalho foi utilizado como elemento fundamental no chamado "tratamento moral" (Sousa, 2001, p. 60). Supunha-se não haver no louco a capacidade de gerir-se na vida social e no trabalho. Em seu caso, o trabalho deveria ter função corretiva - a de reintroduzi-lo no reino dos normais -, pois a indicação rigorosa do trabalho era o principal elemento do tratamento moral. No Brasil essa lógica se reproduziu com o esforço de Teixeira Brandão em constituir, no final do século XIX, asilos identificados no modelo de colônias (Amarante, 1982). Marca-se, dessa forma, que somente se autorizaria o trabalho para essas pessoas com uma única significação: como tratamento. Podemos supor que aqueles internos atribuíam às atividades que realizavam sentidos diversos - muito além daquele suposto pela equipe profissional em sua ação prescritiva -, mas esses sentidos não ganharam visibilidade. Notamos também que hoje, duzentos anos mais tarde, quando se propõe para essas pessoas a realização de tarefas nas chamadas "oficinas terapêuticas", elas desejam dessa experiência muito mais que o "terapêutico", remetendo a questões ligadas à possibilidade de autonomia, reconhecimento via remuneração etc.

As tentativas de transformação da psiquiatria ocorridas no século XX designaram um importante lugar para o trabalho dos usuários ${ }^{3}$. Marca-se o grande alcance que a obra de Hermann Simon - conhecida, sobretudo, através do livro de 1929, Por uma terapêutica mais ativa no hospital psiquiátrico (Billiard, 2001, p. 104) - alcançou, de modo que a ergoterapia por ele proposta teve grande influência nas reformas psiquiátricas, em especial na França, no

2 É o próprio Taylor (1911/1990, p. 34) quem afirma: “(...) em quase todas as artes mecânicas, a ciência que estuda a ação dos trabalhadores é tão vasta e complicada que o operário, ainda o mais competente, é incapaz de compreender esta ciência (...)”.

3 Utilizamos aqui o termo "usuário", coerente com o esforço da psiquiatria democrática italiana de romper com uma tradição psiquiátrica geradora de aprisionamento e de objetivação da pessoa, que os próprios italianos chamaram de "paradigma clínico" (Rotelli, Leonardis \& Mauri, 1990, p. 30). O termo "paciente" pode, no entanto, ser encontrado mais facilmente em textos dos expoentes da Psicoterapia Institucional francesa, como, por exemplo, Tosquelles (Gallio \& Constantino, 1994, p. 95). No Brasil, em serviços que procuram trabalhar de maneira coerente com a reforma psiquiátrica, utiliza-se freqüentemente a palavra "usuário", embora também se fale "paciente", "cliente" e outras. 
movimento da psicoterapia institucional. Cabe ressaltar, ainda, que o trabalho e o seu questionamento tiveram nos hospitais psiquiátricos franceses uma importância tão grande que o nascimento da psicopatologia do trabalho teve seu começo ali, como mostra Billiard (2001). A autora destaca a participação de Sivadon e Le Guillant, considerados pioneiros daquela disciplina, além de Veil, dentre outros.

Mais tarde, o que ficou conhecido como psiquiatria democrática italiana também buscou ressaltar e valorizar o trabalho dos usuários, criando a idéia da empresa social, na qual o seu trabalho é tomado, não como terapia, mas principalmente como forma de garantia de remuneração e de inserção social (Leonardis, Mauri \& Rotelli, 1995). Não pretendemos neste texto estabelecer pontos de concordância ou de divergência entre os diversos movimentos de reforma psiquiátrica, tampouco no que diz respeito à maneira como procuravam ver o trabalho dos usuários ${ }^{4}$. Sabemos que entender o trabalho como terapia ou não e, portanto, atribuir ou não uma remuneração a ele é uma discussão necessária, assim como determinar com maior precisão a importância que as alterações psicopatológicas podem exercer na atividade de trabalho de uma pessoa. Estamos, por enquanto, marcando apenas que o que se entendia por trabalho e a psiquiatria caminharam lado a lado desde o início desse ramo da medicina e, no entanto, compreendemos ainda hoje muito pouco o que o trabalho (e sua organização) pode trazer de positivo ou de negativo para as pessoas com transtornos mentais graves. Além disso, como dissemos, sabemos que elas têm tido pouquíssimas oportunidades de trabalhar, sendo por vezes impedidas de realizar até mesmo atividades domésticas em suas próprias casas. Assim, já que o trabalho "(...) nunca é neutro em relação à saúde e favorece seja a doença, seja a saúde" (Dejours, 1998, p. 164), cabe hoje conhecer melhor o que o trabalho, ou a sua ausência, tem trazido para os usuários dos serviços de saúde mental.

\section{Reflexões a respeito do trabalho}

Por ser nossa intenção pensar o trabalho na sua relação com as pessoas com transtornos mentais graves cabe, agora, indagar sobre seu significado. Como dissemos anteriormente, tomamos a ergologia como fornecedora das principais ferramentas para compreender e transformar o trabalho. Para indagar seu significado e seu lugar na vida dos seres humanos, apontaremos a seguir uma discussão iluminada por reflexões da ergologia, a ser retomada no item subseqüente.

Via de regra, tende-se a pensar no trabalho em um sentido estrito, isto é, tendo a significação de prestação remunerada em uma sociedade mercantil e de direito. Consideramos que essa definição diz respeito a situações que um certo número de pessoas vivencia, mas que é por demais estreita e que é necessário levar em conta complexidades que a noção que acabamos de evocar não dá conta e não engloba.

Schwartz (1995a, p. 419), ao fazer uma breve análise histórica e antropológica do trabalho, deixa claro que ele é inserido nas condições de uma época. Assim, podemos pensar em trabalho na confecção de ferramentas pelo homo habilis há dois ou cinco milhões de anos atrás, ou nas organizações sociais no neolítico relacionadas com a produção agrícola, ou, mais recentemente, na instituição do salariato com a emergência do capitalismo. Em cada um

\footnotetext{
4 Certamente, esse não é um campo sem contradições mesmo dentro de cada um de seus movimentos. No caso da psicoterapia institucional, por exemplo, embora ela reconheça a inspiração na ergoterapia, encontramos textos de seus expoentes, como Oury e Le Guillant, que lhe dirigem severas críticas. Da mesma forma, os italianos não negam a necessidade da terapêutica, mas admitem que novas estruturas precisam ser inventadas e que a terapêutica no asilo leva provavelmente à produção de mais exclusão.
} 
desses momentos pode-se considerar o trabalho de maneiras diferentes. Desse modo, pensar o trabalho sem levar em conta suas condições históricas é argumentar sobre o abstrato.

Nesse sentido, vários textos mostraram como certas concepções sobre o trabalho em uma época específica foram, por um lado, determinadas por circunstâncias históricas e, por outro, produziram um sentido para o trabalho das pessoas com transtornos mentais. Conforme dissemos, Foucault (1987, p. 73), por exemplo, mostra como a idéia de que os loucos tinham "(...) incapacidade para o trabalho e incapacidade de seguir os ritmos da vida coletiva" foi fundamental para justificar a invenção do hospício por Pinel. Neste artigo levantamos algumas questões que surgem na contemporaneidade, quando se pensa o trabalho em relação a pessoas com sofrimento mental grave e a necessidade de compreender e transformar essa realidade.

A noção de trabalho que adotamos tem como ponto de partida que ele tem sempre participação do ser humano. Em função disso, há no trabalho características relativas ao humano todo o tempo, trazendo aspectos histórico-culturais e aspectos singulares de cada pessoa. Ao considerar assim o trabalho, não podemos nos furtar a admitir que nele há complexidades que nenhuma simplificação pode dar conta. Tomar o trabalho como prestação remunerada em uma sociedade mercantil de direito é possível apenas pontuando-se que essa definição insere uma das possibilidades do que se apresenta em nossos dias, fruto de transformações históricas que, a partir do século XVIII, passam a tomar o trabalho como fonte de riqueza (Castel, 2001, p. 213). Não podemos nos esquecer que, mesmo sendo hoje o salariato a forma hegemônica, ao seu lado subsistem diversas outras. Além disso, histórica e antropologicamente outras modalidades de trabalho existiram, de modo que podemos dizer que essa forma atual não será eterna.

A ergonomia da atividade, também chamada de ergonomia francofônica, afirma que “(...) não é a atividade em si, mas sua finalidade, que caracteriza o trabalho" (Guérin, Laville, Daniellou, Duraffourg \& Kerguelen, 2001, p. 16). Ela acentua que se deve considerar sempre os elementos presentes em um dado momento (singular, mas atravessado por elementos histórico-sociais) durante a realização do trabalho. Sendo as circunstâncias histórico-sociais, por definição, mutáveis, o trabalho é sempre inserido em um determinado momento da história e com ela muda. Como afirma Schwartz, "nada do que se joga ao nível das atividades industriosas é sem pertinência, via entidades hesitantes historicamente engendradas, para os níveis visíveis da vida social, e vice-versa" (1995b, p. 594).

Em função dessa injunção problemática entre o social e cada pessoa, ambos com suas variabilidades, Schwartz (1989, p. 280) faz uma afirmação que, diferentemente dos ergonomistas, não coloca o social como determinante na situação de trabalho. Na medida em que toma o trabalho como usos de si, pelos outros e por si mesmo, afirma que cada um - em qualquer momento e lugar que seja - há que negociar esses usos para realizar a atividade de trabalho e atribuir importância à atividade. Como dissemos, a definição dos ergonomistas remete à tentativa de definir o trabalho, marcando a separação entre o que pode ou não ser assim nomeado. Considerando que no trabalho há sempre atividade, situam o centro da análise não na atividade ela mesma, mas na finalidade.

O problema que se coloca, neste caso, é do reconhecimento do trabalho de pessoas historicamente ditas incapazes de trabalhar, para quem o trabalho se coloca freqüentemente apenas como terapia, conforme pontuamos anteriormente. A atividade, sempre presente em todo trabalho, ganha em uma determinada época e lugar significado de trabalho ou apenas de atividade sem o sentido de trabalho, seja ela lúdica ou outra. Ao analisar-se a relação entre o trabalho e as pessoas com transtornos mentais, percebe-se que elas historicamente têm sido colocadas à margem dos regimes hegemônicos. No hospício, geralmente, quando há atividade de pacientes - freqüentemente há pouca, visto que a maioria das pessoas fica ociosa -, ela raramente é considerada trabalho ou é remunerada. 
Como o trabalho é sempre atividade, há sempre circulação entre o que é assim considerado e uma outra atividade não reconhecida socialmente como tal. Afirmamos, desse modo, que é impossível definir precisamente o que é o trabalho - aquilo que pode ou não ser enquadrado nesta categoria - sem deixá-lo circunscrito em uma definição submetida a um determinado contexto social, histórico ou econômico e sem excluir as pessoas que não se adequam àquele modelo sócio-econômico.

\section{Inspiração na ergologia: trabalho e pessoas com transtornos mentais graves}

Neste item apresentaremos a maneira como, a partir de nossa compreensão de conceitos da ergologia, podemos pensar o trabalho em relação às pessoas com transtornos mentais graves. A abordagem ergológica situa-se na tradição de Canguilhem, para quem a vida é entendida "(...) como atividade de oposição à inércia e à indiferença" (Canguilhem, 1999, p. 173). A atividade é considerada um élan de vida e de saúde, característico de todo ser vivente, que atravessa o corpo e a mente, o coletivo e o individual, sem limite preciso e impossível de se definir. Sendo ela algo próprio do vivente, é impossível ao humano ficar passivo frente ao que lhe é prescrito. Assim, há sempre algo que o humano cria frente ao que lhe é pedido, o que abre um caminho para se pensar em trabalho de pessoas que historicamente foram consideradas incapazes de trabalhar, já que a maneira como uma pessoa insere-se no trabalho, seja ela quem for, nunca será dada previamente, pois "se a vida é um trabalho no qual o vivente experimenta e se experimenta, então, se ela é 'improvisação', concebe-se que as 'tentativas' de vida são numerosas" (Nouroudine, 2001, p. 88).

Se, como dissemos, para compreender o trabalho há que se considerar as condições conceituais e históricas nas quais cada pessoa é confrontada (Schwartz, 1995a, p. 418), como pensar o trabalho de homens e mulheres portadores de transtornos mentais graves sem considerar o fato de que sobre eles pesam duzentos anos de história da psiquiatria? A psiquiatria, a seu modo, concedeu um caráter de cientificidade ao julgamento acerca da relação dessas pessoas com o trabalho enquanto incapacidade, pessoas para quem o trabalho somente se prestaria como terapia. Esse julgamento, hegemônico em nossa sociedade, exerce influência sobre essas pessoas? Pensamos que sim, pois sabemos que os saberes psi criaram uma série de idéias, daí tomadas como verdadeiras e que precisam ser questionadas para que essas pessoas possam viver - e bem - em sociedade (Basaglia, 1985, p. 104).

Cada situação específica de trabalho apresenta como uma de suas características a presença de normas antecedentes, no sentido que as entende Schwartz. Elas "(...) reenviam, por um lado, no nosso universo social a nós, a isto que é da ordem das relações de poder ou das relações de propriedade. Dito de outra forma, há uma dimensão (...) que reenvia à edição de princípios, ao colocar em funcionamento estratégias decididas em outro lugar e que se pede às pessoas para executar" (Schwartz \& Durrive, 2003, p. 70), isto é, ao enquadramento de uma situação antes da realização de uma atividade. E ainda: "estas normas antecedentes cristalizam sob uma forma tendencialmente codificada, 'autorizada', (...) as aquisições da inteligência e da experiência coletiva - deste modo mais ou menos recebidas como um bem 'de todos'(...)" (Schwartz, 1995b, p. 598), por mais que o considerado "bem de todos" suporte toda uma ambivalência a propósito de quem compõe esse "todos". Telles (2002, pp. 22-23), ressalta que pelo menos três elementos devem ser considerados com relação às normas antecedentes: elas representam restrições heterodeterminadas à execução; são construções históricas; indicam valores. Cada situação de trabalho, então, apresenta, da parte daquele que o solicita, uma série de formalizações, prescrições, determinações hierárquicas, acordos entre os diversos níveis daquela organização e da sociedade na qual ela está inserida, elementos que 
se constituem em normas antecedentes. Frente a isso, cabe a cada trabalhador gerir essas normas a partir de suas próprias características e valores a fim de realizar o trabalho.

Em cada situação de trabalho há ressingularizações que o humano, por ser vivente e por ser humano, realiza, visto ser impossível a uma pessoa fazer o que lhe pedem sem que algo de pessoal se coloque naquela situação, sem que ela tente fazer aquele meio de vida e trabalho como seu (Canguilhem, 1947), de modo que “(...) o trabalho real não é a estrita aplicação do trabalho prescrito (...)" (Schwartz, 1988, p. 41).

Quando a pessoa com transtorno mental defronta-se com as situações de trabalho, cabe a ela compreender e negociar com as normas antecedentes e renormalizar, como qualquer outra pessoa. Mas entendemos que no seu caso é necessário, ainda, lidar com as eventuais dificuldades que as alterações psicopatológicas podem trazer. Além disso, o que já não seria pouco, a história dos saberes psi criaram uma série de saberes socialmente difundidos, como dissemos, que tendem a despotencializar essa pessoa frente a uma situação de trabalho.

Podemos perguntar: quais são as construções históricas sobre a capacidade de trabalhar e de conviver em sociedade da pessoa com transtorno mental grave? Quais são os valores socialmente compartilhados quanto a isso? Como dissemos, a psiquiatria nasce isolando o louco do convívio social, decretando sua incapacidade para o convívio e, portanto, para atividades coletivas. $O$ hospício constituiu-se como lugar de administração das figuras de miséria, periculosidade social, marginalidade e improdutividade (Barros, 1994). A noção de "doença mental" estabeleceu socialmente os valores de que o "doente" é incapaz de responsabilizar-se pelos atos da vida civil, de trabalhar e de gerir a si mesmo no trabalho. Embora a expressão "demência precoce" (Bercherie, 1989, p. 172), que Kraepelin tomou emprestada de Morel, não seja conhecida da maioria das pessoas, a idéia de que o sujeito que enlouquece torna-se demente, incapaz, improdutivo é amplamente difundida.

$\mathrm{Na}$ descrição que a CID-10 apresenta da esquizofrenia, semelhante ao que traz o DSM-IV, encontra-se o seguinte texto:

Os transtornos esquizofrênicos se caracterizam em geral por distorções fundamentais e características do pensamento e da percepção, e por afetos inapropriados ou embotados. Usualmente mantem-se clara a capacidade intelectual, embora certos déficits cognitivos possam evoluir no curso do tempo. Os fenômenos psicopatológicos mais importantes incluem o eco do pensamento, a imposição ou o roubo do pensamento, a divulgação do pensamento, a percepção delirante, idéias delirantes de controle, de influência ou de passividade, vozes alucinatórias que comentam ou discutem com o paciente na terceira pessoa, transtornos do pensamento ou sintomas negativos ${ }^{5}$ (Organização Mundial de Saúde, 1993, p. 85).

Esse é o primeiro parágrafo da referida descrição. Embora a CID-10 diga que o curso evolutivo deteriorante não ocorre todas as vezes, vemos que das três frases que compõem esse pequeno texto, todas terminam com afirmativas que anunciam o curso degradante, ou seja: "afetos (...) embotados", "déficits cognitivos (...) no curso do tempo", "sintomas negativos". Nessa tríade: o embotamento afetivo é a crescente incapacidade de sentir e expressar os sentimentos, os déficits cognitivos reduzem a inteligência e os sintomas negativos são o empobrecimento geral do funcionamento psicomotor. Vemos que tal fragmento de texto (que se pretende cientificamente neutro) traz logo de início, finalizando cada uma de suas frases, a descrição (não seria "prescrição"?) da baixa significativa do funcionamento pessoal. Não estamos negando aqui que a esquizofrenia e outras entidades nosológicas descritas no capítulo cinco da CID-10, que aborda os transtornos mentais e comportamentais, existam de fato. Não pretendemos negar toda a tradição dos saberes psi no que eles têm de reconhecimento

5 Os grifos em itálico são nossos. 
das disfunções e das possibilidades de intervenção em favor do humano que daí derivam. No entanto, afirmamos que tais conhecimentos trazem muitas vezes um conteúdo que acaba por tornar ainda mais difícil a vida dessas pessoas.

O julgamento de incapacidade dessas pessoas, então, tende a participar o tempo todo no trabalho. Mas é exatamente na atividade que se criam condições de transformar as normas antecedentes e mesmo os limites pessoais de cada ser humano, ampliando sua capacidade produtiva, entendemos que o trabalho pode ser lugar de desenvolvimento pessoal dos portadores de transtornos mentais graves, na medida em que negociam com aquele julgamento social que supõe sua incapacidade e buscam recursos pessoais para dar conta de realizar a atividade, cuidando para se apropriar daquele meio de vida como seu, desenvolvendo, assim, potencialidades que nem elas mesmas sabiam possuir.

Como dissemos, entendemos com a ergologia que trabalhar envolve sempre, de algum modo, mesmo que no infinitamente pequeno, ressingularizar, criar suas próprias normas, colocar à prova as normas antecedentes, pois todo trabalho é lugar onde se joga uma dramática, ali é a pessoa inteira que se coloca, havendo sempre no trabalho formas de gestão de si mesmo. Assim, trabalhar é gerir, expressão que mostra as escolhas que se há de fazer (Schwartz, 1994, p. 434).

Seguimos Schwartz quando afirma que podemos tomar todo trabalho como lugar de uma dramática singular onde serão negociados para cada um a articulação dos usos de si pelos "outros" e "por si". Assim, toda atividade de trabalho “(...) é lugar e ocasião de 'dramáticas do uso de si”" (Schwartz, 1996, p. 78) na qual estão o tempo todo em jogo valores, debates de normas, onde o infinitesimal comunica-se com os níveis mais globais da vida histórica e social, ou seja, onde interagem o histórico coletivo com a história pessoal. Desse modo, cabe a cada pessoa, e nesse caso àquela com transtorno mental grave, interagir com esses elementos sócio-culturais e realizar o trabalho a fim de desenvolver sua competência e sua saúde.

Schwartz (1987) diz que, no trabalho, é o indivíduo no seu ser que é convocado, ou seja, a chamada "mão-de-obra" não é apenas "mão", pois ali é a pessoa como um todo que se apresenta. Cada pessoa emprega sua capacidade produtiva a fim de realizar uma atividade, usa sua força de trabalho para produzir algo que se dirige a outrem. Para alcançar esse objetivo, usa seus recursos, suas capacidades, escolhe uma determinada maneira para realizar a atividade. Ou seja, ao receber uma prescrição, há uma reconcepção, uma maneira pessoal de reestruturar aquela prescrição e realizar a atividade. Além disso, o sentido que a pessoa dá à atividade, ou seja, o que esta significa singularmente, e as conseqüências que o trabalho pode ter para ela mudam de acordo com seus desejos e possibilidades em um dado momento. Ocorre, então, no trabalho, o "uso de si por outrem" e o "uso de si por si", visto ser o trabalho algo que se realiza dirigido a um outro, mas há também ali gestão de si, ressingularização, construindo dessa maneira, sua competência, sua saúde, sua identidade. Em função disso, acreditamos que no trabalho a pessoa com transtorno mental grave pode desenvolver novas competências, abandonar a identidade historicamente produzida de pessoa incapaz, construindo sua saúde.

Schwartz (2000, p. 703), ao falar da imprevisibilidade das transformações futuras do espaço social frente ao trabalho, diz que a atividade é sempre fonte de "reservas de alternativas" que podem dar origem a diversas realidades, de modo que na atividade se abrem caminhos que possibilitam transformação social. Entendemos que uma maior visibilidade do trabalho de um grupo, que tradicionalmente foi considerado incapaz de trabalhar, torna possível pensar em formas de organizar o trabalho diferentes daquelas que conhecemos, trazendo ganhos não só para essa população, mas também para a sociedade como um todo.

Podemos dizer, então, que cada vez que uma pessoa com transtorno mental grave se coloca em situação de trabalho - seja em cooperativas, no trabalho doméstico nos lares 
abrigados ou mesmo nos meios ordinários de trabalho, os ditos formal ou informal - criam-se condições para se produzir mudanças, ou seja, criam-se possibilidades de trabalho onde podem ocorrer renormalizações, novas maneiras de trabalhar. Para Schwartz (1995b, p. 594), renormalização é o processo de retrabalho das normas antecedentes que acontece em todas as situações de trabalho, nas quais, frente às variabilidades, as pessoas sempre arbitram os meios para atingir os objetivos fixados.

Neste momento pergunta-se: que uso a pessoa com transtorno mental grave pode fazer de si no trabalho, isto é, que benefícios ela pode ter ao inserir-se em um processo de trabalho? Que uso pode ser feito pelo outro (empresas, cooperativas etc.) da força de trabalho dessas pessoas? Sabemos que elas pessoas raramente têm conseguido se colocar em trabalho, sobretudo no trabalho dito formal, no qual o mercado tão pouco respeita o ser humano. Além disso, diversas iniciativas de cooperativa de trabalho, criadas muitas vezes no próprio seio da reforma psiquiátrica, têm, de modo geral, conseguido se constituir apenas enquanto forma de trabalho protegido, isto é, recebendo facilidades oferecidas pelo Estado, mostrando-se pouco lucrativas e conseqüentemente seus integrantes, via de regra, ganhando nessas estruturas menos do que desejam e do que precisam. Continuam, assim, dependendo do dinheiro da família ou de benefícios da previdência social. Parece-nos, portanto, que ainda é necessário o surgimento de novas formas de possibilidade de inserção dessas pessoas nos mundos do trabalho.

\section{A relação de serviço e o modelo da competência}

Alguns autores identificam desde a década de 1980 a emergência de novas formas de produção no seio do capitalismo. Estamos nos referindo à lógica de produção de serviço e ao modelo da competência. Segundo o economista, sociólogo e consultor de empresas francês Philippe Zarifian, o trabalho industrial assalariado apresenta historicamente três características principais, a saber: a cisão entre trabalho e trabalhador, o fluxo e a produtividade de operações de trabalho como predominantes e a necessidade de co-presença (Zarifian, 2001a, p. 40). Por outro lado, os novos processos de produção de serviço, que superam aquele modelo de trabalho assalariado industrial clássico, requisitam a competência, que "(...) é sobretudo uma abertura e uma transformação interna dos ofícios já existentes" (Zarifian, 2001b, p. 89). Na produção de serviço, o tempo todo o trabalhador realiza suas atividades levando em conta as necessidades e os benefícios aos destinatários. $\mathrm{O}$ autor propõe a seguinte definição de competência: "(...) é a faculdade de mobilizar rede de atores em torno das mesmas situações, é a faculdade de fazer com que esses atores compartilhem as implicações de suas ações, é fazê-los assumir áreas de responsabilidades" (Zarifian, 2001a, p. 74). Dessa definição destacamos três elementos: a mobilização, a co-responsabilidade e a preocupação com as implicações.

Quanto à mobilização, ela é da própria pessoa, diz respeito aos usos que ela faz de si por si, isto é, o quanto e como ela investe de si naquele trabalho. É também a maneira pela qual ela se coloca naquela rede de atores, isto é, o quanto ela oferece da sua capacidade produtiva para trabalhar em grupo, ou seja, oferece um uso de si aos outros, o que remete ao elemento da co-responsabilidade.

Quanto à co-responsabilidade, a pessoa coloca-se junto às outras em uma situação de trabalho. Há aqui preocupações legítimas relativas à necessidade de cooperar e às vezes até de procurar impedir que a outra se coloque em uma situação de risco. Há também cuidado com a qualidade do resultado do seu trabalho, que será oferecido ao destinatário, o que remete às implicações daquele trabalho. 
No que diz respeito à implicação, fica evidente a necessidade do trabalhador comprometer-se tanto com o processo de trabalho, quanto com seu funcionamento, evitando as disfunções e o desperdício. Trata-se também do compromisso com os companheiros de trabalho e com a qualidade do produto ou do serviço, considerando que estes últimos deverão ser utilizados por um destinatário.

Como dissemos, desde a década de 1980, cada vez mais aspectos do trabalho industrial clássico e a visão que se tinha do lugar do trabalhador vão perdendo terreno e a necessidade desse trabalhador desenvolver suas competências vai tornando-se evidente. Essas competências desenvolvem-se e são utilizadas com a automobilização. "Em outras palavras, existe, na lógica da competência, uma dimensão do indivíduo que é inelutável" (Zarifian, 2001a, p. 121).

Esse é um modelo de competência desenvolvido no seio do próprio capitalismo. Não devemos pensar que o sistema tornou-se benevolente, que adequa-se perfeitamente às idiossincrasias que as pessoas com transtornos mentais graves experimentam vez por outra, que deste momento em diante devemos elaborar projetos cujos objetivos não sejam outro senão inserir essas pessoas nas organizações capitalistas. É claro que todo projeto como esse está condenado a ser uma ortopedia sócio-mental, uma tentativa de moldar as pessoas ao que o capitalismo espera delas. Essa seria, certamente, uma maneira de produzir mais e mais sofrimento.

Sabemos que as novas formas de organização do trabalho vieram acompanhadas de novas formas de desfiliação, no sentido em que fala Castel (2001, p. 536), isto é, "ausência de inscrição do sujeito em estruturas portadoras de um sentido, sociabilidades demasiado inconsistentes". De fato, a lógica atual do mercado de trabalho é marcada por um modelo econômico que desde os anos 1980 reavivou a idéia do mercado como sendo algo que "(...) faz parte da 'ordem natural”' (Di Ruzza \& Halevi, 2003, p. 36), que se coloca como guia para a vida das pessoas. Com relação a isso concordamos com os autores que acabamos de citar, para quem é necessário bater contra esse consenso, por ser “(...) logicamente inconsistente, teoricamente falso, socialmente perverso e politicamente perigoso".

Nesse contexto, aquelas novas formas de organização do trabalho coincidiram com um enfraquecimento das funções sociais do Estado e dos movimentos sociais, aumento do desemprego, precarização dos vínculos de trabalho, entre outras desgraças. Esse quadro é fonte de muito sofrimento de trabalhadores, desempregados ou não, de quem se exige esforços e capacidades sobre-humanos (Seligmann-Silva, 1997). Não é nossa proposta adotar uma postura ingênua, exaltando as glórias das novas formas de organização do trabalho, esquecendo os danos que as acompanham. No entanto, pensamos que há pelo menos um aspecto positivo nessas novas organizações do trabalho, em especial para as pessoas com transtornos mentais, que é exatamente requisitar uma mobilização no sujeito que trabalha, ou seja, solicita-se a mobilização de conhecimentos adquiridos e a compreensão da singularidade da situação para agirem adequadamente. Pede-se mobilização, co-responsabilidade, preocupação com as implicações, solicita-se algo que é próprio do humano. Diante de uma tarefa, a pessoa mobiliza-se para dar conta daquela situação de acordo com suas próprias capacidades, com suas próprias normas, desenvolvendo habilidades que antes ignorava possuir, ou que ainda não haviam surgido. É exatamente o que acontece ao colocarem-se em situações de trabalho que desenvolvem capacidades. Tratam-se de capacidades relativas tanto à tarefa propriamente dita, quanto ao convívio com os outros, na medida em que o trabalho tem sempre uma dimensão coletiva e supõe sempre um cliente direta ou indiretamente implicado.

Nas décadas anteriores existia maior chance de se conseguir um emprego estável com direitos trabalhistas, o que, claro, é ótimo e desejável! Os trabalhadores devem ter sempre os direitos respeitados. É fato que as pessoas têm sofrido pressões terríveis com a instabilidade 
crescente ligada à organização do trabalho, fazendo aparecer diversas formas de sofrimento. Por outro lado, todos esses infortúnios parecem por vezes fazer esquecer que o trabalho taylorizado pedia um modelo desumano do humano, na medida em que solicitava um sujeito mecanizado, como ilustra o próprio Taylor (1911/1990, p. 42) quando fala a propósito do posto de trabalho:

(...) o trabalho de cada operário é completamente planejado pela direção, pelo menos com um dia de antecedência e cada homem recebe, na maioria dos casos, instruções escritas completas que minudenciam a tarefa de que é encarregado e também os meios usados para realizá-la.

Entendemos que esse modelo de trabalho e de trabalhador capaz de teoricamente - e apenas teoricamente, já que isso seria impossível de ser vivido para o ser humano - adequarse totalmente a uma tarefa prescrita por outro, exclui a pessoa com transtorno mental dos mundos do trabalho por ser demais rígido e não suportar suas singularidades. Se as novas formas de organizar o trabalho, então, trazem muito de sofrimento, o modelo anterior, taylorizado, também era desumano e tendia a excluir totalmente todos aqueles que não se dispunham ou não conseguiam entrar em um molde prêt à porter.

\section{Trabalho e reforma psiquiátrica no Brasil}

Os manuais de psiquiatria procuram mostrar que as alterações mentais freqüentemente impedem a pessoa de mobilizar suas capacidades. A descrição da CID-10, por exemplo, diz que a esquizofrenia pode trazer alterações fundamentais e características do pensamento, da sensopercepção, do afeto e da consciência do eu (Organização Mundial de Saúde, 1993, p. 85), acarretando grandes dificuldades à pessoa para entender a si mesma, o mundo a seu redor e para comunicar-se. Considerando esses critérios, estaria fora de possibilidade sua inserção nos mundos do trabalho, mesmo no caso do trabalho doméstico. Por outro lado, diversas experiências de trabalho com pessoas com sofrimento mental grave mostram o quanto o trabalho permite-lhes desenvolver suas competências, preocupando-se com o produto e com o cliente, comunicando-se melhor, aumentando sua capacidade de cooperação.

As pessoas que passam por crises decorrentes de transtornos mentais graves, sobretudo as que são hospitalizadas, freqüentemente após recuperarem-se estabelecem pouco contato social, mantêm-se muito dentro de casa e diminuem sua capacidade de cooperação. No entanto, lembramos que é justamente em situações profissionais que as competências se desenvolvem, de modo que, fora do trabalho, sentindo-se inútil em casa, a pessoa dificilmente conseguirá desenvolvê-las. O trabalho funciona, então, como elemento fundamental para a saúde mental de todos, inclusive da pessoa com sofrimento mental grave. Trabalhando ela pode desenvolver sua capacidade empreendedora frente ao que a vida lhe apresenta.

Sabemos que os neurolépticos foram inventados há cinco décadas e que os avanços da psicofarmacologia permitem aos portadores de transtornos mentais grande controle sobre as alterações das funções psíquicas, tanto nas crises, quanto fora delas. Igualmente, diversas psicoterapias desenvolveram-se de modo a permitir que as pessoas possam viver melhor apesar dos próprios transtornos. Não nos deparamos mais com os limites que Pinel e Kraepelin encontraram no que diz respeito àquelas alterações. No entanto, oito décadas após a invenção da Ergoterapia por Simon, com todas as críticas que as diversas correntes da reforma psiquiátrica fizeram a ela, até que ponto as iniciativas de trabalho que temos criado 
no seio da reforma psiquiátrica no Brasil têm de fato possibilitado o crescimento da autonomia dos usuários ou têm sido apenas novas formas (nem tão novas assim) de oferecer "terapia pelo trabalho"?

Quando alguém está desestabilizado, em qualquer esfera da vida, determinadas exigências mercadológicas podem ser muito mais fonte de sofrimento do que abertura de possibilidades de saúde, pois

(...) exigir dos indivíduos mais desestabilizados que se conduzam como sujeitos autônomos? Porque montar um projeto profissional, ou, mais ainda, construir um itinerário de vida, não é uma coisa evidente quando se está, por exemplo, desempregado ou ameaçado de ser expulso da moradia. (...) É verdade que esse tipo de contrato em geral é fictício, porque o impetrante dificilmente está à altura de semelhante exigência (Castel, 2001, pp. 605-606).

Da mesma forma, exigir que uma pessoa com transtorno mental grave se adéqüe às regras do mercado é algo fadado ao fracasso e à frustração, que podem ser vividos tanto ao nível de angústia e desilusão, como também ao nível de problemas financeiros graves, pois uma pessoa licenciada pela previdência social, ao conseguir um trabalho formalmente reconhecido, deve abrir mão de sua licença e possivelmente terá dificuldades para reavê-la ao perder tal emprego.

Para pensar o que o trabalho pode trazer de positivo para a pessoa com transtorno mental, há que se considerar, por um lado, os modos como o trabalho vem sendo organizado na contemporaneidade e, por outro, como têm sido colocadas as oportunidades de trabalho para essas pessoas. Diante disso, perguntamos: o quanto as iniciativas de trabalho propostas pela reforma psiquiátrica têm possibilitado o desenvolvimento da competência dos usuários, isto é, sua mobilização, co-responsabilidade, preocupação com as implicações? As oficinas e cooperativas têm se colocado, de fato, como lugares de "usos de si" que contribuem para que aquela pessoa crie seu meio de trabalho e de vida segundo suas próprias normas? O quanto as experiências de trabalho criadas a partir de unidades de saúde mental têm sido ocasião de reprodução de uma relação técnico/usuário que, por sua vez, reproduz um lugar de submissão? Se no trabalho a pessoa com transtorno mental grave pode renormalizar, contribuindo para a transformação da norma antecedente segundo a qual ela é incapaz, as iniciativas que a Reforma têm criado são, afinal, locais de produção de qualidade e desenvolvimento pessoal dos usuários?

As cooperativas de trabalho podem servir como formas de inserção nos mundos do trabalho em um híbrido dentro-e-fora do mercado formal. No entanto, são usadas muitas vezes, infelizmente dentro dos próprios serviços, como forma de explorar a força de trabalho das pessoas, como tem ocorrido com os chamados técnicos de saúde mental, que comumente trabalham sem ter seus direitos assegurados. Diante disso, podemos perguntar: as formas de organização do trabalho de usuários, com freqüência no modelo de cooperativas, têm de fato contribuído para possibilitar um lugar de reconhecimento social ou tem sido mais uma forma de exploração de mão-de-obra à margem dos direitos trabalhistas e previdenciários?

Em função dos avanços da reforma psiquiátrica no Brasil houve uma significativa redução de leitos em manicômios. Como nesses estabelecimentos havia um grande número de pessoas sem contato com suas famílias ou que, por circunstâncias diversas, seus familiares não teriam condições ou não seria desejável voltar a morar com eles, colocou-se a questão de como fazer para que essas pessoas pudessem viver fora do hospício. Para dar conta dessa problemática, têm sido criadas "residências terapêuticas" para que possam ter onde morar (Portaria n⿳⺈ 106, Ministério da Saúde, 11/02/2000). Nessas residências há a necessidade de realizar tarefas do dia-a-dia da casa, de autocuidado, de negociar as relações com os outros, por isso chamamos atenção para a presença de atividades de trabalho doméstico sendo aí 
realizadas. Podemos perguntar: como os residentes dessas estruturas têm se colocado no trabalho doméstico que realizam? Em que sentido esse trabalho traz possibilidades de autovalorização? Em que medida as negociações feitas com os outros no dia-a-dia, no convívio e durante a divisão/realização das tarefas domésticas são fonte de desenvolvimento pessoal e de promoção da sua própria saúde?

Em que medida, por fim, dar maior visibilidade à atividade de trabalho que essas pessoas realizam nas unidades de saúde mental, nas cooperativas e nas residências terapêuticas pode servir como "reserva de alternativas", permitindo pensar em formas de organização do trabalho que respeitem mais a todos os humanos?

\section{Conclusão}

Procuramos aqui pensar algumas questões com relação à pessoa com transtorno mental grave e o trabalho. Apenas colocamos o problema e sabemos que é necessário ouvir mais o que essas pessoas têm a dizer sobre si no trabalho e vê-las trabalhando mais.

Encontra-se como socialmente predominante a visão construída na história da psiquiatria de que essas pessoas não podem produzir, não se adequam às situações de trabalho, o que acabou por impedir uma aproximação maior dessas pessoas com o trabalho.

Estamos ainda muito longe de poder falar que as pessoas com transtornos mentais graves conseguem se colocar no trabalho de maneira satisfatória para elas, mas as tentativas de transformação da organização do trabalho e da assistência em saúde mental estão ainda em curso, afinal de contas, "no que diz respeito aos sujeitos humanos, ninguém conhece e nem conhecerá integralmente as condições iniciais de seu objeto de estudo, como também ninguém conhece as suas próprias condições. É por isso que a história sempre nos reserva surpresas" (Schwartz, 1987, p. 64).

\section{Referências}

Amarante, P. (1982). Psiquiatria Social e colônia de alienados no Brasil (1830-1920). Dissertação de Mestrado, Instituto de Medicina Social, Universidade do Estado do Rio de Janeiro, Rio de Janeiro.

Barros, D. D. (1994). Cidadania versus periculosidade social: a desinstitucionalização como desconstrução de um saber. In P. Amarante (Org.), Psiquiatria Social e Reforma Psiquiátrica. Rio de Janeiro: Fiocruz.

Basaglia, F. (1977). Qu'est-ce que la psychiatrie? In F. Basaglia (Org.), Qu'est-ce que la psychiatrie? (pp. 13-26). Paris: PUF.

Basaglia, F. (Org.). (1977). Qu'est-ce que la psychiatrie? Paris: PUF.

Basaglia, F. (1985). As instituições da violência. In F. Basaglia (Org.), A instituição negada: relato de um hospital psiquiátrico (pp. 99-133). Rio de Janeiro: Graal.

Basaglia, F. (Org.). (1985). A instituição negada: relato de um hospital psiquiátrico. Rio de Janeiro: Graal.

Bercherie, P. (1989). Os fundamentos da clínica: história e estrutura do saber psiquiátrico. Rio de Janeiro: Zahar.

Billiard, I. (2001). Santé mentale et travail: l'émergence de la psychopathologie du travail. Paris: La Dispute/SNÉDIT. 
Canguilhem, G. (1947). Milieu et normes de l'homme au travail. Cahiers Internationaux de Sociologie, v. 3, 2ème année, (pp. 120-136). Paris: Seuil.

Canguilhem, G. (1999). Le normal et le pathologique (8⿳亠丷厂 ed.). Paris: Quadrige/PUF.

Castel, R. (2001). As metamorfoses da questão social: uma crônica do salário (3ạ ed.). Petrópolis: Vozes.

Dejours, C. (1988). A loucura do trabalho: um estudo de Psicopalogia do Trabalho (5ำ ed.). São Paulo: Cortez-Oboré.

Diário Oficial da União (2000). Portaria $n^{\circ}$ 106/Ministério da Saúde, publicada no DOU em 11 de fevereiro de 2000, Brasília.

Di Ruzza, R. \& Halevi, J. (2003). De l'économie politique à l'ergologie: lettre aux amis. Paris / Budapest: Harmattan / Innoval.

Foucault, M. (1987). História da loucura na idade clássica (2ª ed.). São Paulo: Perspectiva.

Gallio, G. \& Constantino, M. (1994). François Tosquelles, a escola de liberdade. In A. Lancetti (Org.), Saúdeloucura: grupos e coletivos (vol. 4, pp. 85-128). São Paulo: Hucitec.

Guérin, F., Laville, A., Daniellou, F., Duraffourg, J. \& Kerguelen, A. (2001). Compreender o trabalho para transformá-lo: a prática da Ergonomia. São Paulo: Edgard Blücher.

Leonardis, O., Mauri, D. \& Rotelli, F. (1990). Desinstitucionalização, uma outra via. In F. Nicácio (Org.), Desinstitucionalização (pp. 17-60). São Paulo: Hucitec.

Leonardis, O., Mauri, D. \& Rotelli, F. (1995). La empresa social. Buenos Aires: Nueva Visión.

Nouroudine, A. (2001). Techniques et cultures: comment s'approprie-t-on des technologies transferées? Toulouse: Octarès.

Oddone, I. (1981). Redécouvrir l’expérience ouvrière. Paris: Messidor.

Organização Mundial de Saúde (1993). Classificação dos Transtornos Mentais e do Comportamento da CID-10: Descrições Clínicas e Diretrizes Diagnósticas. Porto Alegre: Artes Médicas.

Rotelli, F. \& Amarante, P. (1992). Reformas psiquiátricas na Itália e no Brasil: aspectos históricos e metodológicos. In P. Amarante (Org.), Psiquiatria sem hospício: contribuições ao estudo da reforma psiquiátrica. Rio de Janeiro: Relume-Dumará.

Schwartz, Y. \& Durrive, L. (2003). Travail $\mathcal{E}$ ergologie: entretiens sur l'activité humaine. Toulouse: Octarès.

Schwartz, Y. (1987). Travail et usage de soi. In Y. Schwartz (1992), Travail et philisophie - convocations mutuelles (pp. 43-66). Toulouse: Octarès.

Schwartz, Y. (1992). Travail et philosophie - convocations mutuelles. Toulouse: Octarès.

Schwartz, Y. (1994). Travail et gestion: niveaux, critères, instances. In Y. Schwartz (2000), Le paradigme ergologique ou un métier de philosophe (pp. 433-438). Toulouse: Octarès.

Schwartz, Y. (1995a). Circulations, dramatiques, efficacités de l'activité industreuse. In Y. Schwartz (2000), Le paradigme ergologique ou un métier de philosophe (pp. 417-432). Toulouse: Octarès.

Schwartz, Y. (1995b). De l'inconfort intelectuel ou: comment penser les activités humaines. In Y. Schwartz (2000), Le paradigme ergologique ou un métier de philosophe (pp. 585-634). Toulouse: Octarès.

Schwartz, Y. (1996). Ergonomie, philosophie et exterritorialité. In Y Schwartz (2000), Le paradigme ergologique ou un métier de philosophe (pp. 71-106). Toulouse: Octarès.

Schwartz, Y. (2000). Ergologie, est-ce un métier? In Y Schwartz (2000), Le paradigme ergologique ou un métier de philosophe (pp. 641-736). Toulouse: Octarès.

Schwartz, Y. (2000). Le paradigme ergologique ou un métier de philosophe. Toulouse: Octarès.

Seligmann-Silva, E. (1997). A interface desemprego prolongado e saúde psicossocial. In J. F. Silva Filho \& S. Jardim (Orgs.), A danação do trabalho - organização do trabalho e sofrimento psíquico. Rio de Janeiro: Te Corá. 
Sousa, I. D. S. (2001). A primeira reforma psiquiátrica: uma história do tratamento moral. Dissertação de Mestrado, Instituto de Medicina Social, Universidade do Estado do Rio de Janeiro, Rio de Janeiro.

Taylor, F. (1911/1990). Princípios de administração científica. São Paulo: Atlas.

Telles, A. L. (2002). Trabalhando como loucos: em busca de novas formas de organização do trabalho a partir de um estudo da Cooperativa da Praia Vermelha. Tese de Doutorado, Coordenação de PósGraduação e Pesquisa em Engenharia, Universidade Federal do Rio de Janeiro, Rio de Janeiro.

Zarifian, P. (2001a). Objetivo competência: por uma nova lógica. São Paulo: Atlas.

Zarifian, P. (2001b). Mutação dos sistemas produtivos e competências profissionais: a produção industrial de serviço. In M. Salerno (Org.), Relação de serviço: produção e avaliação (pp. 67-94). São Paulo: Senac.

Endereço para correspondência: paulozamsouza@yahoo.com.br 